\title{
All we ever wanted to know about perioperative bleeding
}

Spahn, Donat R ; Rossaint, Rolf

DOI: https://doi.org/10.1097/EJA.0b013e328361af11

Posted at the Zurich Open Repository and Archive, University of Zurich ZORA URL: https://doi.org/10.5167/uzh-78033

Journal Article

Originally published at:

Spahn, Donat R; Rossaint, Rolf (2013). All we ever wanted to know about perioperative bleeding. European Journal of Anaesthesiology, 30(6):267-269.

DOI: https://doi.org/10.1097/EJA.0b013e328361af11 
Eur J Anaesthesio/ 2013; 30:267-269

INVITED COMMENTARY

\title{
All we ever wanted to know about perioperative bleeding
}

\author{
Donat R. Spahn and Rolf Rossaint
}

European Journal of Anaesthesiology 2013, 30:267-269

This Invited Commentary accompanies the following article:

Kozek-Langenecker SA, Afshari A, Albaladejo P, et al. Management of severe perioperative bleeding. Guidelines from the European Society of Anaesthesiology. Eur J Anaesthesiol 2013; 30:270-382.

In this issue of the Journal, the European Society of Anaesthesiology's (ESA) guidelines on the management of severe perioperative bleeding are published. ${ }^{1}$ These guidelines are part of the ESA's efforts to increase patient safety as declared in the 'Helsinki Declaration on Patient Safety in Anaesthesiology', ${ }^{2}$ and they are the result of more than 2 years of hard work by the task force led by Sibylle Kozek-Langenecker who was mandated by the ESA in 2010.

These guidelines are massive. They comprise 221 recommendation statements, explanations on approximately 70 pages, list 1466 references and cover the following topics: coagulation monitoring; anaemia and coagulation management; multimodal approaches in specific clinical fields; anticoagulation and antiplatelet therapy; and perioperative bleeding management in patients with comorbidities affecting haemostasis or with congenital bleeding disorders. So this is all we ever wanted to know about perioperative bleeding management! We, therefore, encourage everybody to read these guidelines carefully; but can they be read in the same way that we review scientific papers normally? Probably not, because the manuscript is huge and discusses 221 individual issues, but does not provide simple algorithms on how to handle a bleeding case in daily clinical practice. Nevertheless, these guidelines are a valuable source of information for those anaesthesiologists with a particular interest in perioperative bleeding and coagulation. For these individuals, these guidelines should be the basis upon which they create algorithms on how to treat patients in specific situations at their hospitals ${ }^{3,4}$ as well as for educational initiatives. Such local educational programmes and algorithms are vital to transform the knowledge provided within the guidelines into outcome benefits for patients suffering from major bleeding. This is indeed possible as the example of Gorlinger et al. shows. ${ }^{4}$ They created such algorithms (which were based on near patient testing with rotational thromboelastometry) for the individual, specific treatment of coagulation derangements with coagulation factor concentrates and labile blood products. Moreover, they analysed the outcome of patients undergoing cardiac surgery at the Essen University Hospital before and after algorithm implementation between 2004 and 2009. Not only were they able to substantially decrease the number of transfusions of red blood cells and fresh frozen plasma, they also managed to reduce by $50 \%$ the incidence of massive transfusion, take-backs and thrombotic complications. ${ }^{4}$

Creating such algorithms or treatment pathways is not only a demand of the Helsinki Declaration on Patient Safety in Anaesthesiology, ${ }^{2}$ but also a recommendation of the second update of the European Trauma Treatment Guidelines. ${ }^{5}$ In this latter set of guidelines, the authors also recommend the creation of checklists in order to facilitate the consequent implementation of these treatment pathways and a regular assessment of adherence to these institutional algorithms in routine quality management. ${ }^{5}$ Numerous analyses have shown that adherence to institutional algorithms results in more consistent care and improved outcomes for trauma patients, ${ }^{6}$ and conversely, major deviation from algorithms results in a three-fold increase in mortality. ${ }^{7}$ Physicians, therefore, do have an obligation to implement such treatment algorithms. To create a higher awareness for this need, the 'STOP the Bleeding Campaign' was founded. ${ }^{8}$ This campaign aims to reduce the number of trauma patients

From the Institute of Anaesthesiology, University and University Hospital Zurich, Zurich, Switzerland (DRS), Department of Anaesthesiology, University Hospital Aachen, RWTH Aachen University, Aachen, Germany (RR)

Correspondence to Donat R. Spahn, MD, FRCA, Professor and Chairman, Institute of Anaesthesiology, Head Medical, Section Anaesthesiology, Intensive Care Medicine and OR-Management, University Hospital Zurich, 8091 Zurich, Switzerland

Tel: +41 44255 2695; fax: +41 44255 4409; e-mail: donat.spahn@usz.ch 
dying within $24 \mathrm{~h}$ after arrival into hospital due to exsanguination by a minimum of $20 \%$ within the next 5 years.

There is another challenge facing such guidelines; namely the need to be updated regularly. This is particularly important in fields such as coagulation monitoring, trauma-induced coagulopathy and the management of perioperative bleeding, in which new developments are occurring rapidly. After the initial publication of the first European Trauma Treatment Guidelines in $2007,{ }^{9}$ a first update was published in $2010,{ }^{10}$ with a second update in $2013,{ }^{5}$ and some of the recommendations have significantly changed. This is also true for the ESA Guidelines on the management of severe perioperative bleeding; fortunately, a regular update is planned. ${ }^{1}$

The last update of the literature search for the ESA guidelines was in May 2012 and in the meantime some highly important papers in the field of active bleeding have been published. Carson et al. ${ }^{11}$ published a Cochrane meta-analysis of 19 prospective randomised studies comparing the effect of liberal vs. restrictive haemoglobin transfusion triggers in more than 6000 patients. They found that a restrictive transfusion strategy resulted in significantly reduced hospital mortality $(-23 \%)$ and fewer postoperative infections $(-19 \%)$. Carson et al. undertook this meta-analysis after they found that in their own prospective randomised trial (involving elderly patients with acute hip fracture and known coronary artery disease) a restrictive transfusion trigger of symptomatic anaemia or haemoglobin less than $8 \mathrm{~g} \mathrm{dl}^{-1}$ resulted in a mortality of $6.6 \%$ vs. a mortality of $7.6 \%$ (not significant) for patients with a liberal transfusion trigger of less than $10 \mathrm{~g} \mathrm{dl}^{-1}{ }^{12}$ Earlier this year another important prospective randomised trial in acute upper gastrointestinal bleeding was published by Villanueva $e t a l .{ }^{13}$ A more restrictive haemoglobin transfusion trigger $\left(<7 \mathrm{vs} .<9 \mathrm{~g} \mathrm{dl}^{-1}\right)$ again resulted in a lower 45-day mortality, lower rates of rebleeding and a shorter hospital length of stay. Finally, in cardiac surgery, LaPar et $a l^{14}$ showed that the introduction of institutional transfusion guidelines per se resulted in a highly significant reduction in blood transfusions and a $45 \%$ reduction in overall hospital mortality. In summary, these high quality studies confirm that restrictive transfusion triggers, as recommended by the ESA Guidelines, ${ }^{1}$ do indeed reduce mortality in patients bleeding from orthopaedic, cardiac and general surgery and in patients with acute upper gastrointestinal bleeding.

Within the field of trauma care, several highly important papers have also recently been published. Inaba $e t a{ }^{15}$ showed that the lower the fibrinogen concentration at ICU admission, the higher the in-hospital mortality. Interestingly, patients with normal fibrinogen concentrations $\left(>1.8 \mathrm{gl}^{-1}\right)$ had the lowest mortality. This finding is in keeping with the fibrinogen concentration target range of 1.5 to $2.0 \mathrm{~g}^{-1}$ recommended by the ESA guidelines ${ }^{1}$ and the European Trauma Treatment Guidelines. ${ }^{5}$ The importance of early tranexamic acid and fibrinogen administration [in the form of cryoprecipitate in the Military Application of Tranexamic Acid in Trauma Emergency Resuscitation (MATTERs II) study] has been highlighted in two recent papers. ${ }^{16,17}$ In military trauma, it was shown that the early administration of tranexamic acid and fibrinogen both independently decreased mortality. ${ }^{17}$ Raza et al. ${ }^{18}$ investigated hyperfibrinolysis in major trauma patients and demonstrated that the incidence of hyperfibrinolysis, when solely assessed by rotational thrombelastometry, was only $5 \%$. However, when using more sensitive tests such as the plasmin-antiplasmin complex test, $59 \%$ had signs of hyperfibrinolysis. Interestingly, 28-day mortality was 12 times higher in patients with elevated levels of plasmin-antiplasmin complex as compared to those with normal levels of plasmin-antiplasmin complex (and thus no evidence of hyperfibrinolysis). These studies strengthen the recommendations for the early administration of tranexamic acid and fibrinogen following trauma. ${ }^{1,5}$ In addition, they may also have demonstrated a limitation of the current hyperfibrinolysis test of rotational thromboelastometry.

The ESA, therefore, is to be congratulated for the vision to view perioperative bleeding an important topic and the task force commended for their commitment to create these great guidelines; they represent a tremendous collection of information. To help the clinicians in their individual institutions to translate this complex information into practical algorithms, the various national societies could create examples of treatment algorithms for the victims of massive haemorrhage. An example of this are those just published by the German Society of Anaesthesiology and Intensive Care. ${ }^{19}$

We have, therefore, not yet reached our ultimate goal, which is an improved outcome for patients suffering from major bleeding. This requires a never-ending educational effort, the creation and implementation of institutional guidelines and algorithms, a regular assessment of adherence to these algorithms and the follow-up of the patients treated to allow the measurement of long-term outcomes. For specific questions to be answered, further clinical studies will need to be conducted. In this sense, the journey towards the optimal management of the bleeding patient has only just begun.

\section{Acknowledgement}

Assistance with the invited commentary: none declared.

Financial support and sponsorship: Dr. Spahn's academic institute is receiving grant support from: Swiss National Science Foundation, Swiss Society of Anesthesiology, Swiss Foundation for Anesthesia Research, Bundesprogramm Chancengleichheit, CSL Behring and Vifor.

Dr. Spahn was the chairman of the ABC Faculty and is a member of the ABC Trauma Faculty which both are managed by Thomson 
Physicians World GmbH, Mannheim, Germany and sponsored by unrestricted educational grants from Novo Nordisk and CSL Behring GmbH.

In the past 5 years, Dr. Spahn has received honoraria or travel support for consulting or lecturing from the following companies: Abbott, Amgen, AstraZeneca, Bayer, Baxter, B. Braun, Boehringer Ingelheim, Bristol-Myers-Squibb, CSL Behring, Curacyte, Ethicon Biosurgery, Fresenius, Galenica, GlaxoSmithKline, Janssen-Cilag, Merck Sharp \& Dohme-Chibret, Novo Nordisk, Octapharma, Organon, Oxygen Biotherapeutics, Pentapharm (now tem Innovations), ratiopharm, Roche, Schering-Plough, Vifor.

Dr. Rossaint has received research grant funding from CSL Behring, Ingelheim Boehringer, Air Liquide, Biotest, Nycomed, NovoNordisk. He also received honoraria for consulting or lecturing from CSL Behring, NovoNordisk, Bayer Healthcare, Air Liquide and Draeger Medical Deutschland.

Conflicts of interest: none declared.

Comment from the editor: this invited commentary was checked by the editors but was not sent for external peer review. RR is an associate editor of the European Journal of Anaesthesiology.

\section{References}

1 Kozek-Langenecker SA, Afshari A, Albaladejo P, et al. Management of severe perioperative bleeding. Guidelines from the European Society of Anaesthesiology. Eur J Anaesthesiol 2013; 30:270-382.

2 Mellin-Olsen J, Staender S, Whitaker DK, Smith AF. The Helsinki Declaration on Patient Safety in Anaesthesiology. Eur J Anaesthesio/ 2010; 27:592-597.

3 Theusinger OM, Madjdpour C, Spahn DR. Resuscitation and transfusion management in trauma patients: emerging concepts. Curr Opin Crit Care 2012; 18:661-670.

4 Gorlinger K, Dirkmann D, Hanke AA, et al. First-line therapy with coagulation factor concentrates combined with point-of-care coagulation testing is associated with decreased allogeneic blood transfusion in cardiovascular surgery: a retrospective, single-center cohort study. Anesthesiology 2011; 115:1179-1191.
5 Spahn DR, Bouillon B, Cerny V, et al. Management of bleeding and coagulopathy following major trauma: an updated European guideline. Crit Care 2013 (in press).

6 Barleben A, Jafari F, Rose J Jr, et al. Implementation of a cost-saving algorithm for pelvic radiographs in blunt trauma patients. J Trauma 2011 ; 71:582-584.

7 Rice TW, Morris S, Tortella BJ, et al. Deviations from evidence-based clinical management guidelines increase mortality in critically injured trauma patients*. Crit Care Med 2012; 40:778-786.

8 Rossaint R, Bouillon B, Cerny V, et al. The STOP the Bleeding Campaign. Crit Care 2013 (in press).

9 Spahn DR, Cerny V, Coats TJ, et al. Management of bleeding following major trauma: a European guideline. Crit Care 2007; 11:R17.

10 Rossaint R, Bouillon B, Cerny V, et al. Management of bleeding following major trauma: an updated European guideline. Crit Care 2010; 14:R52.

11 Carson JL, Carless PA, Hebert PC. Transfusion thresholds and other strategies for guiding allogeneic red blood cell transfusion. Cochrane Database Syst Rev 2012:CD002042.

12 Carson JL, Terrin ML, Noveck H, et al. Liberal or restrictive transfusion in high-risk patients after hip surgery. N Engl J Med 2011; 365:2453-2462

13 Villanueva C, Colomo A, Bosch A, et al. Transfusion strategies for acute upper gastrointestinal bleeding. $N$ Engl J Med 2013; 368:11-21.

14 LaPar DJ, Crosby IK, Ailawadi G, et al. Blood product conservation is associated with improved outcomes and reduced costs after cardiac surgery. J Thorac Cardiovasc Surg 2013; 145:796-804.

15 Inaba K, Karamanos E, Lustenberger T, et al. Impact of fibrinogen levels on outcomes after acute injury in patients requiring a massive transfusion. $\mathrm{J} \mathrm{Am}$ Coll Surg 2013; 216:290-297.

16 Morrison JJ, Dubose JJ, Rasmussen TE, Midwinter MJ. Military Application of Tranexamic Acid in Trauma Emergency Resuscitation (MATTERs) Study. Arch Surg 2012; 147:113-119.

17 Morrison JJ, Ross JD, Dubose JJ, et al. Association of cryoprecipitate and tranexamic acid with improved survival following wartime injury. JAMA Surg 2013; 148:218-225.

18 Raza I, Davenport R, Rourke C, et al. The incidence and magnitude of fibrinolytic activation in trauma patients. J Thromb Haemost 2013; 11:307-314.

19 Grottke O, Frietsch T, Maas M, et al. Dealing with massive bleeding and associated perioperative coagulopathy: recommendations for action of the German Society of Anaesthesiology and Intensive Care Medicine. Anaesthesist 2013; 62:213-224. 